\title{
Satisfação no trabalho e oportunidades de desenvolvimento da carreira entre profissionais com deficiência
}

\author{
Renata Vale ASSUNÇÃO ${ }^{1}$ \\ Maria Nivalda de CARVALHO-FREITAS \\ Marcos Santos de OLIVEIRA \\ Universidade Federal de São João del-Rei, São João del-Rei, MG, Brasil
}

Job satisfaction and career advancement opportunities

for professionals with disabilities

Satisfacción laboral y oportunidades de desarrollo profesional para los profesionales con discapacidad

Resumo

Esta pesquisa buscou identificar se a satisfação das pessoas com deficiência em relação às possibilidades de carreira e desenvolvimento está relacionada aos investimentos das empresas na carreira de seus funcionários. Trata-se de uma pesquisa quantitativa, cujos dados foram analisados estatisticamente. Participaram da investigação 51 pessoas com deficiência ( $\mathrm{PcDs}$ ) de diversos estados brasileiros. Os resultados indicam que, do ponto de vista de trabalhadores com deficiência, as políticas de desenvolvimento da carreira profissional não são claras e explícitas dentro das organizações, e que as formas de gestão de carreira adotadas pelas empresas influenciam diretamente na satisfação das $\mathrm{PcDs}$ em relação às oportunidades de crescimento profissional. Foi possível verificar ainda que as estratégias de contratação de PcDs para cumprimento de uma cota, sem considerar a competência técnica e funcional desses trabalhadores, contribuem para que eles se sintam insatisfeitos com as oportunidades de crescimento profissional.

Palavras-chave:

Pessoas com deficiência; crescimento profissional; satisfação profissional.

\section{Abstract}

This research aimed to identify whether disabled persons' satisfaction with their career opportunities and development is related to company investment in the careers of its employees. This is a quantitative study, whose data were analyzed statistically. The investigation was carried out with 51 people with disabilities $(\mathrm{PwD})$ from several Brazilian states. The results indicate that, from the standpoint of disabled workers, career development policies are not clear and explicit within their organizations, and that the forms of career management adopted by companies directly influence the satisfaction of $\mathrm{PwD}$ regarding opportunities for professional growth. It was also possible to verify that the strategies of hiring $\mathrm{PwD}$ to fulfill a quota, without considering the technical and functional competence of these workers, contributes to making them feel dissatisfied with their opportunities for professional growth.

Keywords:

People with disabilities; professional growth; job satisfaction.

Resumen Este estudio tuvo como objetivo identificar la relación entre satisfacción de las personas con discapacidad en relación con las oportunidades de desarrollo de carrera y la inversión empresarial en la carrera de sus empleados. Se trata de un estudio cuantitativo, cuyos datos fueron analizados estadísticamente. Participaron de la investigación 51 personas con discapacidad ( $\mathrm{PcDs}$ ) de varios estados brasileños. Los resultados indican que, desde el punto de vista de los trabajadores con discapacidad, las políticas de desarrollo de carrera profesional no son claras y explícitas dentro de las organizaciones, y que las formas de gestión de la carrera adop- 
tadas por las empresas influyen directamente en la satisfacción de las PcDs con las oportunidades para crecimiento profesional. También fue posible verificar que las estrategias de contratación son para cumplir con una cuota, sin tener en cuenta la competencia técnica y funcional de estos trabajadores, lo que contribuye en hacer que se sientan insatisfechos con las oportunidades de crecimiento profesional.

Palabras-clave:

Personas con discapacidad; crecimiento profesional; satisfacción laboral.

A

s pessoas com deficiência (PcDs) foram, durante anos, excluídas da vida social, profissional e cultural ou tratadas como incapazes e necessitadas de caridade (Carvalho-Freitas, 2007). A partir da implementação de leis que regularizam a participação dessas pessoas no mercado de trabalho, os indivíduos com deficiência passaram a ter seus direitos assegurados, o que tem impactado na reorganização de várias empresas e ampliado a participação dessas pessoas (Carvalho-Freitas, 2007). No entanto, ainda existem inúmeras barreiras físicas, preconceitos e discriminações que impedem uma inclusão mais efetiva das PcDs na sociedade, principalmente no mercado de trabalho (Ribeiro \& Carneiro, 2009; Silva, 2006), e que dificultam a valorização dessas pessoas em suas capacidades, desenvolvimento e qualidade de vida.

De acordo com o censo realizado em 2010 pelo Instituto Brasileiro de Geografia e Estatística (IBGE), cerca de 46 milhões de brasileiros declararam possuir alguma deficiência (mental, motora, visual ou auditiva), o que corresponde a $24 \%$ da população (IBGE, 2010). A fim de incluir esse contingente de pessoas no mercado formal de trabalho, várias leis e medidas foram criadas com o propósito de oferecer acessibilidade e igualdade de oportunidades e tratamento a pessoas com deficiência (por exemplo, a Lei 8.213/91, conhecida como Lei de Cotas).

É evidente que tais legislações contribuíram para a ampliação da discussão sobre inclusão e divulgação de informações sobre as possibilidades de participação das PcDs no mercado de trabalho, aumentando também a contratação dessas pessoas pelas empresas (Suzano, Nepomuceno, Ávila, Lara, \& Carvalho-Freitas, 2009). Porém, conforme dados da Relação Anual de Informações Sociais (RAIS), divulgados pelo Ministério do Trabalho e Emprego (MTE, 2012), apesar do respaldo da Lei de Cotas e ações para seu cumprimento, o número de pessoas com deficiência empregadas está aquém do número de postos de trabalho propostos pela lei (dos vínculos empregatícios no Brasil, em 2012, 0,7\%, eram relativos à PcDs, o que corresponde a 330.300 pessoas).

O desemprego entre pessoas com deficiência em idade para trabalhar chega a 80\%, índice muito superior ao dos demais indivíduos economicamente ativos (5,5\%, segundo dados do IBGE, 2010). Além disso, apenas um seleto grupo de trabalhadores com deficiência, que atuam nas maiores empresas brasileiras, ocupam cargos hierarquicamente elevados (1,3\% dos cargos executivos, $0,4 \%$ dos cargos de gerência, $0,6 \%$ dos cargos de supervisão e 1,5\% dos cargos funcionais), o que comprova que, apesar das políticas conquistadas, esse segmento encontra-se distante de alcançar uma inclusão satisfatória no mercado de trabalho (Instituto Ethos, 2010).

De acordo com uma pesquisa realizada por Ribeiro e Ribeiro (2012), as oportunidades de carreira para pessoas com deficiência têm contribuído para um ambiente de trabalho mais inclusivo, baseado na diversidade, muito embora ainda existam estigmas e preconceitos nas culturas organizacionais, nas quais esse processo acontece mais por obrigação legal do que por um contexto de mudança que se apoia em programas de desenvolvimento de carreira.

Várias pesquisas ratificam a dificuldade de pessoas com deficiência quanto à inserção no mercado formal de trabalho, bem como a insatisfação delas quanto à manutenção ou ao desenvolvimento da carreira dentro das empresas (Bahia \& Schommer, 2010; Caruso, 2012; Carvalho-Freitas, 2007; Carvalho-Freitas \& Marques, 2007; Gödke, 2010; Irigaray \& Vergara, 2011).

Pesquisas que avaliaram a satisfação de pessoas com deficiência em relação a fatores associados à manutenção de qualidade de vida no trabalho (Carvalho-Freitas, 2007; Carvalho-Freitas, Marques, \& Almeida, 2009) demonstraram que as PcDs, de uma forma geral, estão satisfeitas com a remuneração, condições de trabalho, relação com colegas e chefia e respeito aos seus direitos. Contudo, estão insatisfeitas com as oportunidades de crescimento profissional e possibilidade de carreira. Tendo esse cenário como referência, o objetivo desta pesquisa foi identificar a percepção das PcDs sobre as formas de gestão de suas carreiras nas empresas, bem como o impacto dessas formas sobre a satisfação com o trabalho e com as oportunidades de desenvolvimento profissional dentro da organização. 
Inicialmente, ressalta-se que a concepção de trabalho adotada neste estudo é de um trabalho que não só oferece condições econômicas ao trabalhador, mas principalmente, fornece sentido à vida do indivíduo, permite o desenvolvimento de habilidades e capacidades e possibilita um sentimento de ser útil e pertencente à sociedade. Além disso, ao conceder possibilidades de desenvolvimento ao trabalhador, o trabalho também beneficia a própria organização (Carvalho-Freitas \& Marques, 2007; Morin, Tonelli, \& Pliopas, 2007).

Sant'Anna, Kilimnik e Moraes (2011), ao apresentarem os modelos considerados clássicos em qualidade de vida no trabalho (QVT) indicam a satisfação como uma expressão possível dos estados psíquicos gerados pela QVT. Segundo Walton (1973), satisfação ou insatisfação no trabalho são respostas emocionais à percepção dos trabalhadores sobre seu trabalho, que podem desencadear ações no campo psicológico ou comportamental. Para o autor, a insatisfação com o trabalho afeta a maioria dos trabalhadores em um ou outro momento, independentemente da posição ou status ocupado, gerando custos individuais e organizacionais. Acredita-se que um alto grau de insatisfação pode levar o trabalhador a desenvolver doenças relacionadas ao trabalho, além de reduzir seu desempenho e produtividade (Carlotto \& Câmara, 2008).

Segundo Sant'Anna et al. (2011), o termo qualidade de vida no trabalho tem sido definido de diferentes formas pelos diversos autores ao longo do tempo. No entanto, as definições têm em comum a acepção de QVT como um instrumento de maior humanização do trabalho, aumento do bem-estar dos trabalhadores e maior participação desses nas decisões e nos problemas do trabalho.

Embora o termo QVT seja mais amplo, Walton (1973) o utiliza para descrever e defender certos valores ambientais e humanos muitas vezes negligenciados pelo avanço industrial. A QVT teve origem no início do século XX, a partir da criação de legislações que regulamentavam as condições de trabalho, tais como a delimitação da carga horária de oito horas e as normas de segurança. A partir de então, foram sendo criadas leis para garantir a igualdade de oportunidades de emprego e considerações relativas às necessidades e aspirações humanas (Walton, 1973).

Walton (1973) propõe oito fatores que, se existentes nos contextos ocupacionais, garantiriam a manutenção da qualidade de vida no trabalho: (a) compensação justa e adequada, (b) segurança e saúde nas condições de trabalho, (c) oportunidade de uso e desenvolvimento da capacidade, (d) oportunidade para crescimento contínuo e segurança, (e) integração social na organização de trabalho, (f) constitucionalismo na organização de trabalho, (g) trabalho e espaço total de vida e (h) relevância social do trabalho. A resposta emocional a esses fatores de QVT tem sido utilizada em pesquisas com pessoas com deficiência, visando identificar a satisfação ou insatisfação destas nos contextos de trabalho (Carvalho-Freitas, 2007; Carvalho-Freitas et al., 2009). Além desses fatores considerados relevantes para a QVT, Hackman e Oldham (1975) destacam a necessidade de crescimento pessoal como variável importante na mediação da relação entre as características do trabalho e os resultados alcançados, cabendo à organização mantê-la e incentivá-la ou diminuí-la e liquidá-la.

Em relação ao crescimento pessoal, Dutra (2011) define a carreira profissional como as séries de estágios e transições de posições ocupadas e trabalhos realizados ao longo da vida de uma pessoa, que variam de acordo com as influências sobre o indivíduo, originadas de suas próprias aspirações e das imposições e expectativas da organização e da sociedade, e estão em constante desenvolvimento e alteração. A carreira nas organizações, tradicionalmente, era associada a um caminho profissional que possibilitava avanços em ocupações e posições ao longo do tempo, possibilitando sucesso e ascensão social. Este modelo é típico de um emprego estável, em organizações com diversos níveis hierárquicos, em que os empregados almejam alcançar o sucesso a partir de uma promoção na carreira (Tolfo, 2002).

Bendassolli (2009) analisa modelos emergentes de carreira, que se contrapõem à carreira tradicional. Tais modelos pressupõem mudanças nas concepções de organização, em que "estruturas mais flexíveis, projetointensivas, menos hierarquizadas, orientadas para gestão de conhecimento, dependentes de criatividade e de outras competências" (p. 395) coexistem nas teorias e nas práticas de gestão de recursos humanos, com o pressuposto de que o indivíduo constrói sua carreira independentemente das organizações. No entanto, tanto os modelos tradicionais de carreira quanto os modelos emergentes convivem no mundo do trabalho atualmente e, segundo Ribeiro e Ribeiro (2012), é tarefa do setor de Recursos Humanos (RH) mediar os interesses e necessidades dos empregados e da organização.

A partir da gestão de carreira voltada para a conformidade entre interesses individuais e organizacionais, Ribeiro (2009) compreende a carreira como uma relação dialética entre o projeto social, ou realidade objetiva, e o projeto de vida individual, ou realidade subjetiva. Projeto, deste modo, é a escolha que o indivíduo faz para 
superar as condições do presente e determinar seus gestos e ações para uma mudança futura (Sartre, 1966). O projeto tem por finalidade modificar a realidade e, por meio dele, o homem realiza a produção de si mesmo no mundo como totalidade objetiva. Entretanto, o filósofo não delega totalmente ao homem a responsabilidade pela superação da situação objetiva, mas também considera o atrelamento da realidade social e histórica, uma vez que nesse transformar e recriar, que vai da escolha até a concretização, ocorre uma tensão da objetivação da subjetividade, na qual o projeto pode ser desviado pelos instrumentos coletivos e assim, a objetivação final talvez não corresponda à escolha original (Sartre, 1966).

Dutra (2011) sugere, a fim de se ter melhores condições de identificar as oportunidades de carreira, que antes de pensar acerca das possibilidades oferecidas pelo ambiente a pessoa deve identificar em si mesma o que gosta, o que a estimula e a satisfaz, ainda que variáveis financeiras, afetivas e necessidades influenciem essa decisão. Neste sentido, Dutra (2011) e Kilimnik (2000) citam pesquisas realizadas por Schein (1990), nas quais este autor descreve categorias de planejamento ou orientações da carreira profissional baseadas em metas pessoais e classificadas por oito âncoras de preferência no desenvolvimento da carreira. São elas:

- Competência gerencial (Âncora 1), na qual classificam-se pessoas cuja motivação principal é serem competentes em atividades gerenciais;

- Competência técnica e funcional (Âncora 2), na qual situam-se pessoas que privilegiam sua área de especialização e habilidades;

- Segurança e estabilidade (Âncora 3), em que se encontram pessoas que privilegiam empresas com vasto horizonte profissional, bom programa de benefícios e aposentadoria e segurança de trabalho;

- Criatividade (Âncora 4), em que classificam-se pessoas cuja principal motivação é criar algo próprio e ter a extensão de si mesmas em um produto ou empresa;

- Autonomia e independência (Âncora 5), na qual distribuem-se pessoas que visam a liberdade e responsabilização pelo resultado do trabalho;

- Senso de serviço e dedicação à causa (Âncora 6), na qual dispõe pessoas que voltam suas carreiras para seus próprios valores de influenciar a humanidade em determinada direção e que desejam ser reconhecidas socialmente pelo que fazem;

- Desafio constante (Âncora 7), na qual situam-se pessoas que acreditam que o sucesso está atrelado a vencer desafios e resolver problemas complexos;

- Estilo de vida integrado (Âncora 8), na qual posicionam-se pessoas cuja motivação principal é a integração entre suas necessidades como indivíduo e da sua família com a carreira profissional.

A âncora de carreira na vida profissional de uma pessoa baseia-se no projeto de vida construído por ela e visa um constante crescimento e mudança, podendo ser utilizada ao longo de uma trajetória profissional para organizar experiências, identificar áreas de contribuição, criar critérios de tipos de trabalho e definir padrões de sucesso e realização para a pessoa (Kilimnik, 2000). A identificação das âncoras de carreira pode, por um lado, promover uma compreensão das pessoas acerca de sua relação com o trabalho e levá-las a um empreendimento de possíveis ajustes dessa relação e, por outro, possibilitar às organizações o desenvolvimento de políticas que possam ajustar os talentos e habilidades individuais às necessidades da empresa (Kilimnik, 2000).

Portanto, neste artigo, a partir da bibliografia estudada, entende-se por gestão da carreira profissional o processo de movimento funcional que implica uma relação entre as expectativas, competências e qualificações individuais em busca de uma ocupação profissional mais satisfatória, e as estratégias adotadas pelas organizações para incentivo e apoio para o desenvolvimento de seus funcionários (Dutra, 2011; Kiliminik, 2000; Ribeiro, 2009).

\section{MÉTODO}

\section{Participantes}

A amostra foi constituída por 51 pessoas com deficiência, sem deficiência intelectual, que ocupam diferentes cargos de organizações de segmentos diversos dos seguintes Estados do Brasil: Espírito Santo, Goiás, Minas Gerais, Paraná, Rio de Janeiro, Rio Grande do Sul, Santa Catarina e São Paulo.

Dentre as pessoas envolvidas na amostra investigada, prevalecem pessoas do sexo masculino (62,7\%); entre as faixas etárias de 46 a 52 anos (25,5\%); que trabalham há mais de 9 anos na organização (37,3\%); com deficiência física $(70,6 \%)$, seguidas pelas deficiências auditiva $(21,6 \%)$, visual $(3,9 \%)$ e outros tipos de deficiência 
(3,9\%); pós-graduadas (37,3\%); com rendimento mensal de 2 a 4 salários mínimos (31,4\%). Além disso, são pessoas com maior predominância em cargos funcionais $(80,4 \%)$, isto é, que exercem funções operacionais, de nível técnico médio ou superior e auxiliares ou assistentes, assim como também revela o Instituto Ethos (2010) em relação à população brasileira. No entanto, esta amostra demonstra particularidades em relação a outras pesquisas com trabalhadores com deficiência, na medida em que é predominantemente composta por pessoas com idade mais avançada e com maior grau de escolaridade, em relação à média nacional. Por outro lado, corrobora uma maior inserção de pessoas com deficiência física e auditiva e uma menor parcela de pessoas com deficiência visual (MTE, 2012).

\section{Instrumentos}

Foram utilizados um questionário sobre gestão e desenvolvimento de carreira, desenvolvido para essa pesquisa com base na literatura estudada, e um fator do inventário de qualidade de vida no trabalho (Oportunidade para crescimento contínuo e segurança), baseado nos modelos de Walton (1973), adaptado por CarvalhoFreitas (2007) para a utilização com pessoas com deficiência.

O questionário sobre gestão e desenvolvimento de carreira foi elaborado a partir da revisão de literatura sobre administração da carreira profissional (Bendassolli, 2009; Dutra, 2011; Kilimnik, 2000; Oliveira, 2003). Tal questionário foi constituído por onze questões iniciais referentes à caracterização do respondente (consideradas na caracterização da amostra) e dois blocos de questões: o primeiro com 20 questões sobre a gestão da carreira dos funcionários em geral, e o segundo com 12 questões relativas à gestão da carreira de funcionários com deficiência, respondidas de acordo com uma escala tipo Likert de seis pontos (1 - discordo totalmente a 6 - concordo totalmente), além de uma questão de assinalar sobre as âncoras de carreira.

Por sua vez, o inventário de qualidade de vida no trabalho é composto por oito fatores $(\alpha=0,97)$. O fator Oportunidade para crescimento contínuo e segurança, foco da presente pesquisa, é composto por seis itens e $\alpha=0,93$, respondidos por meio de uma escala de satisfação de seis pontos (de 1 - totalmente insatisfeito a 6 - totalmente satisfeito) (Carvalho-Freitas, 2007).

\section{Procedimentos de coleta de dados e cuidados éticos}

O questionário sobre gestão e desenvolvimento de carreira e o inventário de qualidade de vida no trabalho foram hospedados na página institucional da universidade em que foi realizada a pesquisa, por meio da plataforma Google Forms, cujo endereço eletrônico foi encaminhado por e-mail a cada participante. O e-mail contendo o objetivo da pesquisa e o endereço eletrônico dos questionários foi divulgado, por quatro vezes, uma por semana (como forma de que não fosse confundido com spam), às pessoas cadastradas em um banco de dados existente no núcleo de pesquisa em que foi desenvolvida o presente estudo. Além disso, houve divulgação para associações de pessoas com deficiência de todo o Brasil e também em grupos de PcDs existentes na internet.

Antes de acessarem as questões, os respondentes deveriam ler e concordar com o termo de consentimento livre e esclarecido e cadastrarem seus e-mails. Os questionários foram "travados" de forma que o respondente só poderia responder a questão seguinte após ter respondido à questão anterior, o que contribuiu para evitar dados faltosos ou respostas parciais aos questionários.

\section{Procedimentos de análise de dados}

Buscando agrupar as questões em fatores, utilizou-se a técnica Smallest Space Analysis - SSA, que permite uma análise com diversos itens, independentemente do tamanho da amostra, a fim de reduzir o número de variáveis e aglomerá-las em fatores a partir de sua forte correlação, uma vez que a SSA é baseada na ordem dos coeficientes de correlação (Bloombaum, 1970). Para aplicação dessa técnica, foi utilizada a ferramenta de Escala Multidimensional (Alternating Least Squares SCALing - ALSCAL) disponibilizada pelo programa SPSS (Statistical Package for the Social Sciences).

Assim sendo, as questões relativas à gestão de carreira foram reunidas e os resultados gerados pela SSA permitiram agrupar as 32 questões em quatro fatores. A consistência interna desses agrupamentos foi avaliada pelo Alfa de Cronbach (coeficiente $\alpha$ ) e indicou, para os itens analisados, que existe uma alta consistência entre eles. (Fator 1 - Investimento da empresa na carreira de profissionais com deficiência: $\alpha=0,97$; Fator 2 Investimentos da empresa na carreira de funcionários em geral: $\alpha=0,90$; Fator 3 - Formas de gestão da carreira adotadas pela empresa: $\alpha=0,93$; Fator 4 - Investimento na carreira adotadas pelos funcionários na empresa e 
feedback: $\alpha=0,89)$. Contudo, a configuração do espaço euclidiano indicou a necessidade de suprimir alguns itens do questionário por dispersarem-se significativamente do conjunto de dados, demonstrando uma perda de relação entre os demais itens nos agrupamentos (outliers).

Nas análises dos dados, adotou-se como variável dependente o fator de QVT (Walton, 1973) - Oportunidade para crescimento contínuo e segurança - e como variáveis independentes foram tomados os quatro fatores de desenvolvimento e gestão da carreira, as variáveis sociodemográficas e as oito âncoras de carreiras. Dessa forma, as variáveis independentes consideradas na pesquisa foram: investimentos da empresa em profissionais com deficiência; investimentos da empresa nos funcionários em geral; formas de gestão de carreira adotadas pela empresa; investimento na carreira adotadas pelos funcionários na empresa e feedback; cargo (gerência ou funcional); tempo de trabalho (até 5 anos ou mais de 5 anos); escolaridade (até ensino médio completo ou graduação e/ou especialização); salário (até 4 salários ou mais de 4 salários mínimos); tipo de deficiência (auditiva e visual ou física); idade (até 40 anos ou mais de 40 anos); sexo; e satisfação com o trabalho. Todas as variáveis relacionadas às âncoras foram consideradas e tinham como possíveis respostas somente Sim ou Não.

A relação entre oportunidades de crescimento profissional e gestão da carreira foi verificada por meio da análise de regressão linear múltipla, em dois blocos. Dessa forma, buscou-se identificar as variáveis específicas para a predição da satisfação com as oportunidades de desenvolvimento profissional, ou seja, o quanto as variáveis de gestão de carreira explicam o referido fator de QVT (bloco 1) e se há mudanças na presença de outras variáveis (bloco 2).

Os modelos de regressão foram construídos por meio do método steprwise, no qual a seleção de entrada das variáveis preditivas é feita estatisticamente e não por hipóteses teóricas prévias. No método stepwise, são fornecidos vários modelos de regressão, com diferentes combinações de variáveis independentes, seguindo uma ordem decrescente de importância explicativa para as variações ocorridas. Assim, a diferença no percentual explicado $\left(R_{\text {ajustado }}^{2}\right)$, quando se compara o segundo bloco de análise com o primeiro, indica o quanto as variáveis sociodemográficas e as âncoras de carreira acrescentam ao modelo explicativo, para além do que as variáveis de gestão da carreira já explicaram. Além disso, foi calculado o índice de Durbin-Watson, que testa se os resíduos adjacentes ao plano de regressão são correlacionados e corrobora a hipótese de distribuição normal dos dados quando seus valores são próximos ou superiores a 2 .

\section{RESULTADOS E DISCUSSÃO}

\section{Análise da satisfação com o fator Oportunidades de crescimento profissional}

Com relação aos dados da Tabela 1, os respondentes dessa pesquisa apresentaram um grau intermediário entre insatisfação e satisfação $(M=3,54 ; D P=1,46)$ com as oportunidades de crescimento profissional na organização, de forma semelhante a resultados de outras pesquisas (Carvalho-Freitas, 2007; Carvalho-Freitas \& Marques, 2007; Gödke, 2010, Irigaray \& Vergara, 2011; Ribeiro \& Ribeiro, 2012). No entanto, apresentam-se satisfeitos $(M=4,06 ; D P=1,60)$ com a segurança quanto ao futuro na instituição em que trabalham.

TABELA 1. Oportunidades de crescimento profissional

\begin{tabular}{|c|c|c|}
\hline Itens do questionário & $M$ & $D P$ \\
\hline Com as oportunidades de promoção, que a instituição oferece, para que eu progrida na carreira profissional & 3,10 & 1,78 \\
\hline $\begin{array}{l}\text { Com as oportunidades, que a instituição oferece, para que eu desenvolva novos conhecimentos e/ou habi- } \\
\text { lidades relativas à minha função }\end{array}$ & 3,41 & 1,61 \\
\hline $\begin{array}{l}\text { Com as possibilidades que tenho para aplicar os conhecimentos adquiridos (nos cursos realizados) no } \\
\text { desenvolvimento de minhas atividades }\end{array}$ & 3,59 & 1,60 \\
\hline Com as oportunidades que tenho para "crescer" na realização de meu trabalho & 3,61 & 1,72 \\
\hline $\begin{array}{l}\text { Com as oportunidades, que a instituição oferece, para que eu possa desenvolver novas habilidades (cursos, } \\
\text { planejamento de carreira, etc.) }\end{array}$ & 3,53 & 1,63 \\
\hline Com a segurança que tenho quanto ao meu futuro nesta instituição & 4,06 & 1,60 \\
\hline Resultado dos itens do fator analisados conjuntamente & 3,54 & 1,46 \\
\hline
\end{tabular}




\section{Fatores de gestão de carreira}

Os dados apresentados pela Tabela 2 indicam que os participantes da pesquisa tendem a discordar $(M=3,25$; $D P=1,78)$ de que a empresa em que trabalham investe na carreira profissional de trabalhadores com deficiência. Além disso, a tendência à discordância é maior em relação à preocupação e à busca de estratégias pela empresa para desenvolver a carreira profissional de funcionários com deficiência $(M=3,18)$. Tais resultados são semelhantes a dados de estudos de Gödke (2010) e Ribeiro e Ribeiro (2012).

TABELA 2. Investimento da empresa na carreira de profissionais com deficiência

\begin{tabular}{|c|c|c|}
\hline Itens do questionário & $M$ & $D P$ \\
\hline A empresa preocupa-se com o desenvolvimento da carreira profissional de funcionários com deficiência & 3,18 & 1,93 \\
\hline Os interesses profissionais de funcionários com deficiência são valorizados pela empresa que trabalho & 3,43 & 1,89 \\
\hline $\begin{array}{l}\text { As expectativas de carreira profissional de funcionários com deficiência são consideradas pela empresa que } \\
\text { trabalho }\end{array}$ & 3,22 & 1,87 \\
\hline $\begin{array}{l}\text { A empresa em que trabalho busca estratégias para o desenvolvimento da carreira profissional de seus funcioná- } \\
\text { rios com deficiência }\end{array}$ & 3,18 & 1,85 \\
\hline $\begin{array}{l}\text { A empresa em que trabalho investe em qualificação profissional e treinamento para seus funcionários com defi- } \\
\text { ciência }\end{array}$ & 3,27 & 1,88 \\
\hline Resultado dos itens do fator analisados conjuntamente & 3,25 & 1,78 \\
\hline
\end{tabular}

Os dados apresentados pela Tabela 3 indicam que os participantes da pesquisa tendem a discordar um pouco $(M=3,45 ; D P=1,45)$ que a empresa em que trabalham investe na carreira profissional de seus funcionários em geral. O maior grau de discordância foi quanto à exigência, pela empresa, do desenvolvimento da carreira dos funcionários, com média de 3,14 (tendência a discordar um pouco).

TABELA 3. Investimentos da empresa na carreira de funcionários em geral

\begin{tabular}{|c|c|c|}
\hline Itens do questionário & $M$ & $D P$ \\
\hline O desenvolvimento da carreira profissional é uma preocupação da empresa em que trabalho & 3,73 & 1,73 \\
\hline Para a empresa em que trabalho, as expectativas de seus funcionários são consideradas na gestão de carreira & 3,47 & 1,77 \\
\hline $\begin{array}{l}\text { A empresa em que trabalho busca estratégias para o desenvolvimento da carreira profissional de seus funcio- } \\
\text { nários }\end{array}$ & 3,69 & 1,76 \\
\hline O desenvolvimento da carreira dos funcionários é exigido pela empresa & 3,14 & 1,73 \\
\hline O desenvolvimento da carreira é feito de forma compartilhada e conversada entre a empresa e seus funcionários & 3,33 & 1,78 \\
\hline A empresa em que trabalho possui um programa formal de gestão de carreira & 3,33 & 1,87 \\
\hline Resultado dos itens do fator analisados conjuntamente & 3,45 & 1,45 \\
\hline
\end{tabular}

De acordo com a Tabela 4, os resultados indicam que os respondentes da pesquisa tendem a discordar um pouco $(M=3,88 ; D P=1,52)$ que a organização adota formas de gestão de carreira para seus funcionários em geral, no entanto, quanto aos itens referentes aos investimentos e incentivos por parte da empresa em qualificação profissional e treinamentos para seus funcionários, o grau de concordância dos participantes é superior a 4 (tendência a concordar). 
A empresa em que trabalho valoriza os interesses profissionais de seus empregados

A empresa em que trabalho investe em qualificação profissional para seus funcionários, concedendo, por exemplo, bolsas de estudo, programas de estágio, rotação no trabalho, entre outros incentivos

As oportunidades de vagas na empresa são divulgadas dentro da própria empresa, ou seja, há um recrutamento interno

A Tabela 5 mostra que os respondentes da pesquisa concordam $(M=4,03 ; D P=1,25)$ que os funcionários buscam formas de desenvolver suas carreiras profissionais, mas tendem a concordar menos $(M=3,80 ; D P=1,57)$ que profissionais com deficiência recebam elogios em relação ao trabalho desempenhado. De modo geral, as médias das respostas para os fatores de gestão de carreira variaram entre 3 e 4 , o que indica que os respondentes da pesquisa discordavam pouco ou concordavam pouco com os itens investigados pelo questionário, o que pode indicar que a gestão da carreira dentro das organizações não é uma questão clara e objeto de políticas explícitas, pelo menos do ponto de vista das pessoas com deficiência.

TABELA 5. Investimento na carreira adotadas pelos funcionários na empresa e feedback

\begin{tabular}{|c|c|c|}
\hline Itens do questionário & $M$ & $D P$ \\
\hline Os funcionários buscam formas de desenvolvimento da própria carreira profissional dentro da empresa. & 4,33 & 1,42 \\
\hline Os funcionários procuram participar de treinamentos para melhor cumprimento de suas funções & 4,31 & 1,33 \\
\hline Os funcionários da empresa em que trabalho recebem elogios quanto ao seu desempenho & 4,10 & 1,36 \\
\hline Os funcionários da empresa em que trabalho recebem sugestões e críticas sobre o que podem melhorar & 3,88 & 1,57 \\
\hline Os funcionários com deficiência recebem elogios quanto ao seu desempenho & 3,80 & 1,66 \\
\hline Os funcionários com deficiência recebem sugestões e críticas para melhorarem seu desempenho & 3,98 & 1,64 \\
\hline Resultado dos itens do fator analisados conjuntamente & 4,03 & 1,25 \\
\hline
\end{tabular}

\section{Âncoras de carreira}

A porcentagem de respostas para as alternativas baseadas nas oito âncoras de carreira está representada na Tabela 6. De acordo com os resultados apresentados, os respondentes $(n=51)$ têm uma preferência significativa $(80,4 \%)$ por um trabalho em que possam ter equilíbrio com a vida pessoal. Tal dado pode indicar que os respondentes investem em sua vida profissional, no entanto, tentam também manter seus investimentos na vida pessoal. Além disso, tal como afirmam Sant'Anna et al. (2011), a necessidade de conciliar a vida pessoal com o trabalho é considerada nas decisões de carreira, a partir da família, lazer, segurança e realização profissional. 
TABELA 6. Âncoras de preferência de desenvolvimento da carreira

\begin{tabular}{|c|c|c|}
\hline Âncora de carreira & $n$ & $\%$ \\
\hline $\begin{array}{l}\text { Estilo de vida integrado: Quero ter um trabalho que me permita ter um bom equilíbrio entre minha vida pro- } \\
\text { fissional e minha vida pessoal (família, lazer, etc.) }\end{array}$ & 41 & 80,4 \\
\hline $\begin{array}{l}\text { Senso de serviço e dedicação à causa: Quero trabalhar em uma função que possa beneficiar outras pes- } \\
\text { soas e a sociedade }\end{array}$ & 28 & 54,9 \\
\hline $\begin{array}{l}\text { Criatividade: Quero trabalhar em um cargo que exija criatividade, em que eu possa sempre criar e manifes- } \\
\text { tar minhas ideias }\end{array}$ & 27 & 52,9 \\
\hline $\begin{array}{l}\text { Autonomia e independência: Quero trabalhar em um cargo onde eu possa ter autonomia e independência } \\
\text { para realizar minhas funções e ser responsável por elas }\end{array}$ & 27 & 52,9 \\
\hline $\begin{array}{l}\text { Desfio constante: Quero ter um trabalho que exija de mim a capacidade de vencer desafios constantemente } \\
\text { e resolver problemas }\end{array}$ & 27 & 52,9 \\
\hline $\begin{array}{l}\text { Segurança e estabilidade: Quero atingir segurança e estabilidade em meu emprego, com um bom programa } \\
\text { de benefícios e aposentadoria }\end{array}$ & 25 & 49,0 \\
\hline $\begin{array}{l}\text { Competência técnica e funcional: Quero trabalhar em um cargo que seja da minha formação profissional } \\
\text { específica (técnico ou superior) }\end{array}$ & 24 & 47,1 \\
\hline $\begin{array}{l}\text { Competência gerencial: Quero atingir um cargo gerencial, no qual eu possa dirigir um setor e gerenciar } \\
\text { pessoas }\end{array}$ & 18 & 35,3 \\
\hline
\end{tabular}

Embora 80,4\% dos respondentes ocupem cargos funcionais, apenas 35,3\% têm preferência por cargos gerenciais. Dentre os respondentes, 47,1\% desejam ocupar cargos afins com sua formação profissional (seja ela técnica ou funcional), o que permite inferir que grande parte não trabalha diretamente na área em que se qualificou.

O desejo pela segurança e estabilidade no emprego está evidenciado na concentração de 49,0\% das respostas. Os participantes da pesquisa demonstraram ampla preferência $(52,9 \%)$ por trabalhos em que possam exercer sua independência e autonomia, uso da criatividade e uso da capacidade de resolver problemas e desafios e desejam desempenhar atividades em que possam praticar tais capacidades. No entanto, apresentaram uma preferência ainda maior $(54,9 \%)$ por realizar trabalhos que beneficiem outras pessoas e à sociedade.

\section{Análise da relação entre a satisfação com as oportunidades de crescimento profissional e gestão da carreira entre profissionais com deficiência}

A Tabela 7 apresenta a matriz de correlação e a Tabela 8 os resultados da análise de regressão linear múltipla do fator Oportunidades de crescimento profissional (QVT).

TABELA 7. Matriz de correlações do fator Oportunidades de crescimento profissional (QVT) e as variáveis preditivas

\begin{tabular}{|c|c|c|c|c|c|c|c|}
\hline & 1 & 2 & 3 & 4 & 5 & 6 & 7 \\
\hline OCP & 1,000 & & & & & & \\
\hline FGCAE & $0,865^{\star \star}$ & 1,000 & & & & & \\
\hline IEPD & $0,773^{\star *}$ & $0,755^{\star *}$ & 1,000 & & & & \\
\hline ST & $0,642^{\star *}$ & $0,531^{\star *}$ & $0,425^{\star \star}$ & 1,000 & & & \\
\hline CTF & $-0,168$ & $-0,015$ & 0,051 & $-0,181$ & 1,000 & & \\
\hline ESC & $-0,048$ & $-0,134$ & $-0,166$ & $-0,170$ & 0,101 & 1,000 & \\
\hline TD & $-0,020$ & 0,142 & 0,054 & 0,052 & $-0,036$ & 0,043 & 1,000 \\
\hline
\end{tabular}

Nota. ${ }^{*} p<0,01 . \mathrm{OCP}=$ Oportunidades de crescimento profissional; FGCAE = Formas de gestão da carreira adotadas pela empresa; IEPD = Investimento da empresa em profissionais com deficiência; ST = Satisfação com o trabalho; CTF = Competência técnica e funcional (Âncora 2); ESC = Escolaridade; TD = Tipo de deficiência. 
$\mathrm{Na}$ Tabela 8 estão presentes apenas os resultados das variáveis que foram significativas no modelo final de cada análise, ou seja, o modelo que melhor explica a variação dos escores globais de mudança percebida.

TABELA 8. Análise de regressão linear múltipla do fator Oportunidades de crescimento profissional e as variáveis preditivas

\begin{tabular}{|c|c|c|c|c|c|}
\hline \multicolumn{6}{|c|}{ Bloco 1} \\
\hline Variáveis preditivas & $B$ & $S E$ & $\beta$ & $t$ & $p$ \\
\hline Constante & 0,368 & 0,270 & & 1,364 & 0,179 \\
\hline Formas de gestão da carreira adotadas pela empresa & 0,628 & 0,099 & 0,655 & 6,363 & $0,000^{*}$ \\
\hline $\begin{array}{l}\text { Investimento da empresa em profissionais com deficiên- } \\
\text { cia }\end{array}$ & 0,228 & 0,085 & 0,278 & 2,695 & $0,010^{*}$ \\
\hline
\end{tabular}
cia

$R^{2}$ ajustado $=0,884 ; F(2,48)=85,768 ; p=0,000$. Durbin-Watson $=2,020$

\begin{tabular}{|c|c|c|c|c|c|}
\hline \multicolumn{6}{|c|}{ Bloco 2} \\
\hline Variáveis preditivas & $B$ & SE & $\beta$ & $t$ & $p$ \\
\hline Constante & 0,574 & 0,286 & & 2,003 & 0,051 \\
\hline Formas de gestão da carreira adotadas pela empresa & 0,540 & 0,084 & 0,563 & 6,429 & $0,000^{*}$ \\
\hline $\begin{array}{l}\text { Investimento da empresa em profissionais com deficiên- } \\
\text { cia }\end{array}$ & 0,238 & 0,068 & 0,290 & 3,528 & $0,001^{*}$ \\
\hline Satisfação com o trabalho & 0,645 & 0,187 & 0,222 & 3,453 & $0,001^{*}$ \\
\hline Âncora 2 - Competência técnica e funcional & $-0,441$ & 0,159 & $-0,152$ & $-2,779$ & $0,008^{*}$ \\
\hline Escolaridade & 0,448 & 0,181 & 0,135 & 2,475 & $0,017^{*}$ \\
\hline Tipo de deficiência & $-0,449$ & 0,175 & $-0,138$ & $-2,567$ & $0,014^{*}$ \\
\hline$R^{2}$ ajustado $=0,936 ; F(6,44)=51,829 ; p=0,000$, Durbin- & atson $=2$ & & & & \\
\hline
\end{tabular}

$\mathrm{Na}$ Tabela 8, pode-se perceber que dois fatores de gestão da carreira - Formas de gestão da carreira adotadas pela empresa e Investimento da empresa em profissionais com deficiência - explicam 88,4\% do grau de satisfação para o fator Oportunidades de crescimento profissional, o que indica que os trabalhadores com deficiência sentem-se mais satisfeitos com as oportunidades de crescimento profissional oferecidas pela empresa quando percebem que a organização adota formas de gestão da carreira profissional e investe em seus funcionários com deficiência. Tais resultados corroboram a afirmativa de Veloso et al. (2011), de que a forma de gestão de carreira pela empresa influencia diretamente na percepção dos trabalhadores sobre as oportunidades de crescimento.

Quando outras variáveis são acrescentadas, o poder explicativo do modelo aumenta para 93,6\%, ou seja, o grau de satisfação com as oportunidades de crescimento é ainda maior quando além de perceberem que a organização adota formas de gestão da carreira profissional e que investe em seus funcionários com deficiência, as PcDs sentem-se satisfeitas com o trabalho (em comparação com as que não se sentem satisfeitas) e possuem graduação ou especialização (quando comparadas com as que possuem até ensino médio).

No entanto, a satisfação com as oportunidades de crescimento diminui quando as pessoas possuem como âncora de carreira a competência técnica e funcional (isto é, gostariam de trabalhar na área em que se sentem preparadas técnica e funcionalmente) e têm deficiência física (em comparação com as pessoas que possuem deficiência auditiva ou visual). Esse resultado, confirma empiricamente que as estratégias comumente adotadas pelas empresas de contratar pessoas com deficiência em funções definidas exclusivamente para PcDs, independentemente de que tipo de qualificação profissional elas tenham (Ribeiro \& Carneiro, 2009), contribui para que elas se sintam insatisfeitas com as oportunidades de crescimento profissional.

As demais variáveis independentes não apareceram no modelo de análise de regressão, o que evidencia que tais atributos não foram decisivos no contexto de satisfação com as oportunidades para crescimento profissional para $\mathrm{PcDs}$ que participaram do estudo.

A presente pesquisa permitiu identificar que a satisfação com as oportunidades de crescimento contínuo e segurança (carreira) pode ser explicada pela percepção das $\mathrm{PcDs}$ de que existe, por parte das empresas, investimento na carreira de seus funcionários, incluindo as próprias PcDs. Esse resultado indica que a insatisfação com as possibilidades de carreira por parte das PcDs identificadas em diversas pesquisas (Carvalho-Freitas, 2007; Carvalho-Freitas \& Marques, 2007; Gödke, 2010, Irigaray \& Vergara, 2011; Ribeiro \& Ribeiro, 2012) está associada a uma ausência de políticas claras de carreira nas organizações que incluam os funcionários com 
e sem deficiência e à atribuição de funções às $\mathrm{PcDs}$ que não consideram suas competências e possibilidades técnicas.

As recorrentes estratégias das organizações de contratarem as deficiências (Ribeiro \& Carneiro, 2009), ao invés das pessoas que as possuem, a fim de cumprirem a Lei de Cotas, têm um impacto direto na satisfação desses trabalhadores, especialmente em relação às oportunidades de crescimento profissional. Os resultados da presente pesquisa suscitam indagações para futuras pesquisas, por exemplo: Como essa insatisfação com as oportunidades de crescimento pode impactar a crença das PcDs em si mesmas? Que estratégias elas adotam para manter o trabalho, mesmo quando se veem reduzidas às deficiências que possuem? Será que a manifestação dessas insatisfações por parte das PcDs contribui para a manutenção da discriminação e do estigma em relação a elas? Essas e outras perguntas se colocam em um contexto em que a questão da vulnerabilidade de grupos historicamente excluídos do mundo do trabalho passa a ser objeto de pesquisa e atuação da psicologia organizacional e do trabalho.

É importante salientar que as características dos participantes da pesquisa (número de respondentes, predominância de pessoas que trabalham na organização há mais de nove anos e que possuem deficiência física) limitam as possibilidades de generalização dos resultados, sendo necessárias futuras investigações para confirmar se esses resultados se manteriam com características diferentes da população investigada.

\section{REFERÊNCIAS}

Bahia, M. S., \& Schommer, P. C. (2010). Inserção profissional das pessoas com deficiência nas empresas: Responsabilidades, práticas e caminhos. Organização e Sociedade, 17(54), 439-461.

Bendassolli, P. F. (2009). Recomposição da relação sujeito-trabalho nos modelos emergentes de carreira. Revista de Administração de Empresas, 4(49), 387-400. doi: http://dx.doi.org/10.1590/S0034-75902009000400003

Bloombaum, M. (1970). Doing smallest space analisys. Journal of Conflict Resolution, 14(2), 409-416. doi: doi. org/10.1177/002200277001400311

Carlotto, M. S., \& Câmara, S. G. (2008). Propriedades psicométricas do Questionário de Satisfação no Trabalho (S20/23). PsicoUSF, 13(2), 203-210. doi: http://dx.doi.org/10.1590/S1413-82712008000200007

Caruso, A. (2012). Reverberações da Lei n 8.213/91 à luz das concepções de deficiência: Estudo de caso no contexto do projeto de sensibilização gerencial em uma organização privada de ensino profissionalizante (Tese de doutorado). Recuperado de http://ppfh.com.br/wp-content/uploads/2014/09/Tese-NORMALIZADA.pdf

Carvalho-Freitas, M. N. (2007). A inserção de pessoas com deficiência em empresas brasileiras - Um estudo sobre as relações de concepções de deficiência, condições de trabalho e qualidade de vida no trabalho (Tese de doutorado). Recuperado de http://www.ufsj.edu.br/portal2-repositorio/File/incluir/tese_maria_nivalda.pdf

Carvalho-Freitas, M. N. (2009). Inserção e gestão do trabalho de pessoas com deficiência: Um estudo de caso. Revista de Administração Contemporânea, 13(edição especial), 121-138. doi: doi.org/10.1590/s1415-65552009000500009

Carvalho-Freitas, M. N., \& Marques, A. L. (2007). A inserção de pessoas com deficiência em empresas brasileiras: Uma dimensão específica da diversidade nas organizações. Anais eletrônicos do XXXI Encontro da Associação Nacional dos Programas de Pós-Graduação em Administração. Rio de Janeiro: EnANAPAD. Recuperado de http://www.anpad.org.br/admin/pdf/ EOR-B879.pdf

Carvalho-Freitas, M. N., Marques, A. L., \& Almeida, L. A. D. (2009). Pessoas com deficiência: Comprometimento organizacional, condições de trabalho e qualidade de vida no trabalho. Gerais: Revista Interinstitucional de Psicologia, 2(2), 92-105.

Dutra, J. S. (2011). Administração de carreiras: Uma proposta para repensar a gestão de pessoas. São Paulo: Editora Atlas.

Gödke, F. (2010). A inclusão excludente dos trabalhadores com deficiência nos processos produtivos industriais (Tese de doutorado). Recuperado de http://www.ppge.ufpr.br/teses/D10_godke.pdf

Hackman, J. R., \& Oldham, G. (1975). A new strategy for job enrichment. California Management Review, 17(4), 57-71. doi: doi. org/10.2307/41164610

Instituto Brasileiro de Geografia e Estatística (2010). Pesquisa nacional por amostra de domicílios: Síntese de indicadores. Rio de Janeiro: IBGE. Recuperado de http://www.ibge.gov.br/home/estatistica/populacao/trabalhoerendimento/pnad2009/ pnad_sintese_2009.pdf

Instituto Ethos de Empresas e Responsabilidade Social (2010). Perfil social, racial e de gênero das 500 maiores empresas do Brasil e suas ações afirmativas: Pesquisa 2010. São Paulo: Instituto Ethos. Recuperado de http://www1.ethos.org.br/ EthosWeb/arquivo/0-A-eb4Perfil_2010.pdf 
Irigaray, H. A. R., \& Vergara, S. C. (2011). O tempo como dimensão de pesquisa sobre uma política de diversidade e relações de trabalho. Cadernos EBAPE.BR, 9(4), 1085-1098.

Kilimnik, Z. M. (2000). Trajetórias e transições de carreiras profissionais em recursos humanos (Tese de doutorado não publicada) Universidade Federal de Minas Gerais, Minas Gerais.

Lei $n^{\circ}$ 8.213, de 24 de julho de 1991 (1991, 24 de julho). Dispõe sobre os planos de benefícios da previdência social e dá outras providências. Recuperado de http://www.planalto.gov.br/ccivil_03/leis/L8213cons.htm

Ministério do Trabalho e Emprego (2012). Características do emprego formal segundo a Relação Anual de Informações Sociais RAIS. Recuperado de http://portal.mte.gov.br/rais/

Morin, E., Tonelli, M. J., \& Pliopas, A. L. V. (2007). O trabalho e seus sentidos. Psicologia \& Sociedade, 19(edição especial), 4756. doi: doi.org/10.1590/s0102-71822007000400008

Oliveira, M. R. C. T. (2003). Impacto do treinamento no desempenho e na carreira: Um estudo com alunos de pós-graduação lato-sensu de uma empresa de serviço de energia elétrica (Dissertação de mestrado). Recuperado de http://www. bibliotecadigital.ufmg.br/dspace/handle/1843/FACE-5SDGMG

Ribeiro, M. A. (2009). Trabalho e loucura: Possibilidades de carreira para pessoas em situação psicótica. Revista Mental, 7(12), 97-117.

Ribeiro, M, A., \& Carneiro, R. (2009). A inclusão indesejada: As empresas brasileiras face à lei de cotas para pessoas com deficiência no mercado de trabalho. Revista Organizações \& Sociedade, 16(50), 545-564. doi: http://dx.doi.org/10.1590/ S1984-92302009000300008

Ribeiro, M. A., \& Ribeiro, F. (2012). O desenvolvimento da carreira de pessoas com deficiência em empresas: Dificuldades e perspectivas. Gerais: Revista Interinstitucional de Psicologia, 5(1), 127-145.

Sant'Anna, A. S., Kilimnik, Z. M., \& Moraes, L. F. R. (2011). Antecedentes e evolução do movimento em torno da qualidade de vida no trabalho. In A. S. Sant'Anna \& Z. M. Kilimnik (Orgs.), Qualidade de vida no trabalho: Abordagens e fundamentos (pp. 23-34). Belo Horizonte: Elsevier - Campus.

Sartre, J. P. (1966). Questão de método. São Paulo: Difusão Europeia do Livro.

Schein, E. H. (1990). Career anchors and job/role planning: The links between career pathing and carrer development. Revista September, 1-21.

Silva, L. M. (2006). O estranhamento causado pela deficiência: Preconceito e experiência. Revista Brasileira de Educação, 11(33), 424-461. doi: doi.org/10.1590/s1413-24782006000300004

Suzano, J. C. C., Nepomuceno, M. F., Ávila, M. R. C., Lara, G. B., \& Carvalho-Freitas, M. N. (2009). Análise da produção acadêmica nacional dos últimos 20 anos sobre a inserção da pessoa com deficiência no mercado de trabalho. In M. N. Carvalho-Freitas \& A. L. Marques (Orgs.), Trabalho e pessoas com deficiência: Pesquisas, práticas e instrumentos de diagnóstico (pp. 23-42) Curitiba: Juruá editora.

Tolfo, S. R. (2002). A carreira profissional e seus movimentos: Revendo conceitos e formas de gestão em tempos de mudanças. Revista Psicologia: Organização e Trabalho, 2(2), 39-63.

Veloso, E. F. R., Dutra, J. S., Fischer, A. L., Pimentel, J. E. A., Silva, R. C., \& Amorim, W. A. C. (2011). Gestão de carreira e crescimento profissional. Revista Brasileira de Orientação Profissional, 12(1), 61-72.

Walton, R. E. (1973). Quality of working life: What is it? Cambridge: Harvard University Press. 